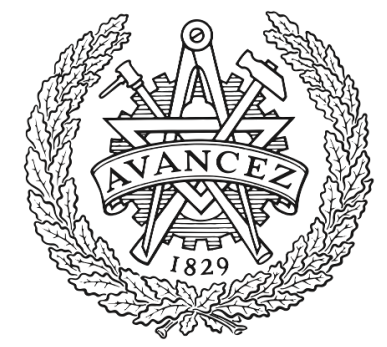

CHALMERS

UNIVERSITY OF TECHNOLOGY

\title{
Efficient Millimeter-Wave High Power Generation with Spatial Power-Combined Feeding Element
}

Downloaded from: https://research.chalmers.se, 2023-04-26 06:54 UTC

Citation for the original published paper (version of record):

Roev, A., Maaskant, R., Höök, A. et al (2018). Efficient Millimeter-Wave High Power Generation with Spatial Power-Combined Feeding Element. IET Conference Publications. http://dx.doi.org/10.1049/cp.2018.0937

N.B. When citing this work, cite the original published paper. 


\title{
Efficient Millimeter-Wave High Power Generation with Spatial Power-Combined Feeding Element
}

\author{
Artem Roev, Rob Maaskant, Anders Höök, and Marianna Ivashina
}

Published in:

12th European Conference on Antennas and Propagation

\section{Author's version before peer-review}

Please check the document version of this publication:

- A submitted manuscript is the author's version of the article upon submission and before peer-review. There can be important differences between the submitted version and the official published version of record. People interested in the research are advised to contact the author for the final version of the publication, or visit the DOI to the publisher's website.

- The final author version and the galley proof are versions of the publication after peer review.

- The final published version features the final layout of the paper including the volume, issue and page numbers.

\section{General rights}

Copyright and moral rights for the publications made accessible in the public portal are retained by the authors and/or other copyright owners and it is a condition of accessing publications that users recognize and abide by the legal requirements associated with these rights.

- Users may download and print one copy of any publication from the public portal for the purpose of private study or research.

- You may not further distribute the material or use it for any profit-making activity or commercial gain

- You may freely distribute the URL identifying the publication in the public portal.

Take down policy

If you believe that this document breaches copyright please contact us providing details, and we will remove access to the work immediately and investigate your claim. 


\title{
Efficient Millimeter-Wave High Power Generation with Spatial Power-Combined Feeding Element
}

\author{
Artem Roev ${ }^{1}$, Rob Maaskant ${ }^{1}$, Anders Höök ${ }^{2}$, and Marianna Ivashina ${ }^{1}$ \\ ${ }^{1}$ Department of Electrical Engineering, Chalmers University of Technology, Gothenburg, Sweden, roev@chalmers.se, \\ rob.maaskant@chalmers.se, marianna.ivashina@chalmers.se \\ ${ }^{2}$ SAAB AB, Gothenburg, Sweden, anders.hook@saabgroup.com
}

\begin{abstract}
An efficient transition from a grid of amplifiers to a single substrate integrated waveguide (SIW) is presented. It is based on the excitation of the spatially distributed SIW mode with an array of parallel and strongly coupled microstrip lines (MLs), each of which is connected to an amplifier. The proposed configuration is optimized by minimizing the 'active' reflection coefficients at the TL ports. This equalizes the amplifier optimal load impedances and excites the TE10 SIW mode most efficiently. Also, signals are transferred with nearly uniform power distribution at the amplifier outputs. Numerical results show that this configuration can generate 16x more power per unit volume relative to a single microstripto-SIW transition, while offering a larger bandwidth. A prototype has been developed to validate the proof-of-concept.
\end{abstract}

Index Terms - mm-wave integrated active antennas, substrate integrated waveguide, spatial power combining.

\section{INTRODUCTION}

The continued growth of data traffic in $5 \mathrm{G}$ wireless communication applications, short-range radars, and satellite communications, demands utilization of multi-antenna systems at higher (mm-wave) frequencies [1-2]. Mm-wave frequencies allow the use of $\mathrm{GHz}$ bandwidths and, hence, significantly enhances the data rate and systems throughput. However, efficient generation and transmission of high RF power is a major challenge at mm-wave frequencies, due to the increased propagation and material losses as well as output power limitations of semiconductor technologies.

Monolithic microwave integrated circuits (MMICs) are traditionally based on Gallium Arsenide (GaAs) wafer processes. However, such circuits are expensive in mass production and complex to use for highly integrated structures, such as digital beamformers or radio modems for cellular handsets. Silicon technologies are more cost effective and more suitable for integration, but their maximum output power is limited due to their relatively low breakdown voltage [2]. This problem can be overcome by using many low-cost active devices per unit volume and combine them using series and parallel power combining techniques [3]. However, the latter solutions are potentially lossy since power is typically combined to a single point before leaving the MMIC. We propose a solution to this problem.

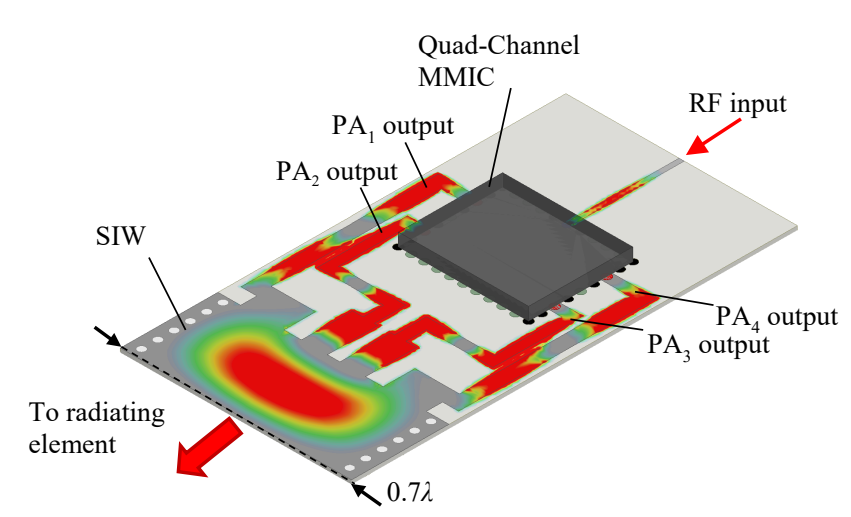

Fig. 1. Illustration of the proposed concept of the transition interfacing four amplifiers situated inside an (NXP) MMIC chip to a single substrate integrated waveguide (SIW).

Another challenge is the integration with radiating elements that are comparable in size at mm-wave frequencies.

This paper presents a novel concept of the transition that can be employed between a single radiating element and an array of amplifiers to facilitate such integrated solutions. Figure 1 illustrates this transition, where an array of four amplifiers (situated inside a chip) is interfaced with a single substrate integrated waveguide (SIW) through four spatially distributed microstrip lines. Initial results for the spatially distributed SIW excitation have been presented in [4], where it was compared to a conventional single-channel tapered transition [5]. In addition to exciting printed circuit antennas, the SIW structure can be also be used to excite a metal waveguide in a direct contactless manner [6].

The goals of the current work are:

(i) To describe the design methodology, including the optimization of the transition for a given field excitation (the focus is on compactness of the SIW structure for potential applications in antenna arrays, and efficient utilization of power amplifiers that should be driven by equal powers); and

(ii) To design a proof-of-concept prototype, which demonstrates the predicted gain in performance, i.e. $16 \mathrm{x}$ higher power generation per unit volume in comparison to a single transition case. This also 
includes specific considerations for testing multichannel transitions with a two-port only calibration.

\section{NUMERICAL RESULTS}

Figure 2(a) shows the geometry of the proposed transition, and Fig. 2(b) illustrates the field propagation inside the SIW as well as the field coupled to the microstrip TLs when the SIW port is excited by the TE10 mode (i.e. receive mode). Due to strong electromagnetic coupling between microstrip TLs [see Fig. 2 (b)], the active reflection coefficients of the microstrip TLs should be considered in the transmitting situation to optimize the design.

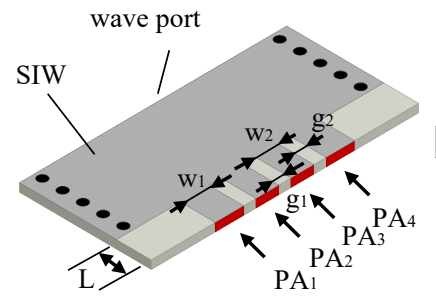

(a)

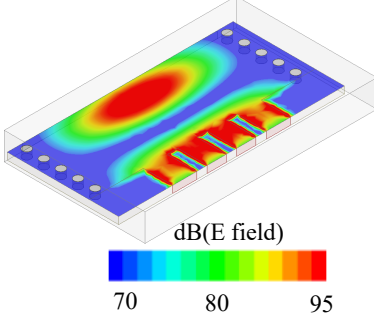

(b)
Fig. 2: (a) The EM model of the proposed multi-channel transition and optimization parameters; (b) Simulated $E$-field amplitude distribution at 31.5 $\mathrm{GHz}$ (real part).

With the reference to Fig. 2(a), the structure employs the RT4350 laminate with thickness $0.254 \mathrm{~mm}$ and relative dielectric constant of $\varepsilon_{\mathrm{r}}=3.66$. The width of the considered SIW is $7.11 \mathrm{~mm}$. The diameter and distance between vias are $0.3 \mathrm{~mm}$ and $0.63 \mathrm{~mm}$, respectively. The optimum design parameters for achieving the best active impedance match are (in mm): $L=1.07 ; w_{1}=0.71 ; w_{2}=0.88 ; g_{1}=0.37 ; g_{2}=0.38$.

The $50-\mathrm{Ohm}$ simulated active and passive reflection coefficients $\left(\Gamma_{1}, \Gamma_{2}, \mathrm{~S}_{11}\right.$ and $\left.\mathrm{S}_{22}\right)$ in the desired frequency range (27.5-31.5 GHz) are shown in Fig. 3. As one can see, the proposed multi-channel transition demonstrates wide bandwidth performance (50\% relative bandwidth) with both $\left|\Gamma_{1}\right|$ and $\left|\Gamma_{2}\right| \leq 20 \mathrm{~dB}$.

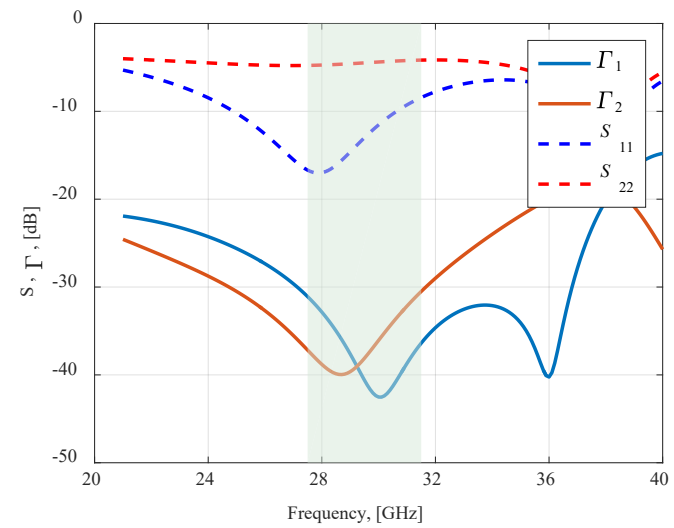

Fig. 3. Simulated active and passive (dashed lines) reflection coefficients of the $50 \Omega$ microstrip ports of the simulated transition, as shown in Fig.2. The colored region shows the operational bandwidth.
Figure 4 shows the microstrip port powers when the SIW port is excited by $1 \mathrm{~W}$ (i.e. receive mode). The power distribution is nearly uniform ( $250 \mathrm{~mW}$ per channel is ideal) in the desired frequency range, implying that the power amplifiers in the array are utilized effectively. The performance degradation that is visible near $40 \mathrm{GHz}$ is due to higher-order SIW modes. This was deemed acceptable and necessary to retain sufficient design freedom for optimizing the transition between 27.5 and $31.5 \mathrm{GHz}$.

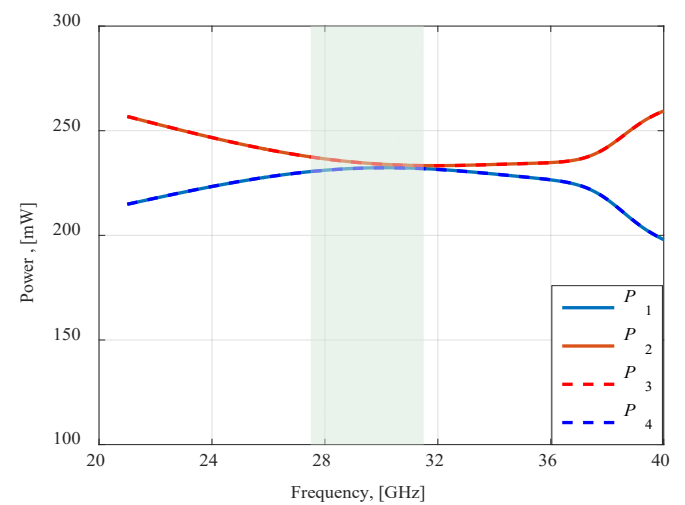

Fig. 4. Simulated power accepted by the microstrip ports when the wave port is excited by $1 \mathrm{~W}$.

Figures 5 and 6 show the simulation results for the routing of the $50-\mathrm{Ohm}$ microstrip lines to be able to mount $\mathrm{RF}$ connectors to the PCB and to decouple the microstrip lines. To achieve the same electrical length of the transmission lines, their physical length has been slightly tuned. After combination, $\left|\Gamma_{1}\right|$ and $\left|\Gamma_{2}\right|$ are well below $30 \mathrm{~dB}$ within the desired frequency range $(27.5-31.5 \mathrm{GHz})$.

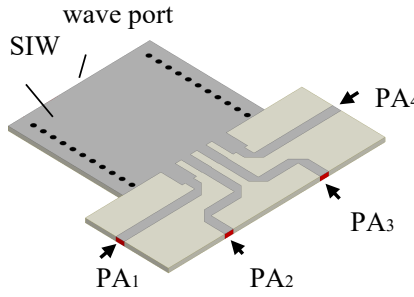

(b)

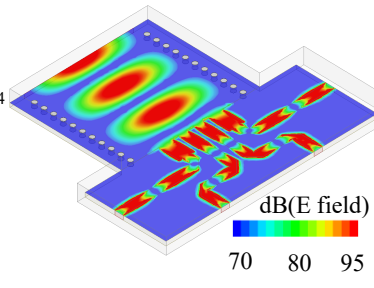

(b)
Fig. 5: (a) Proposed transition including the array of short parallel transmission lines and the routing of the microstrip lines; (b) Magnitude of $E$-field distribution at $31.5 \mathrm{GHz}$ (real part).

The power distribution remains nearly uniform across the transmission line ports (see Fig. 7). However, the average level of the accepted power becomes a bit lower $(8 \%$ relatively to the previous case) due to losses in the bent microstrip TLs. It was verified that by adding the TLs to the connectors, the performance due to mutual coupling effects was not degraded and that the effects of these extra line lengths can be removed through a calibration procedure. 


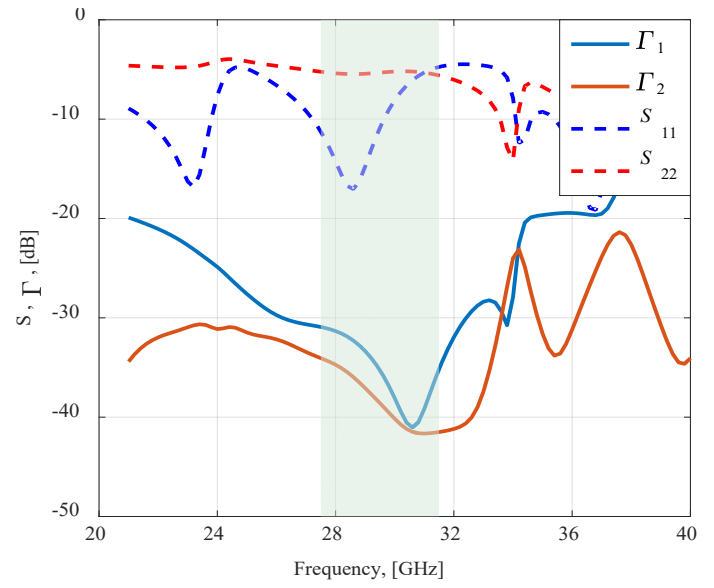

Fig. 6. Simulated active (solid) and passive (dashed) reflection coefficients of the $50-\Omega$ microstrip ports $\left(\mathrm{Pa}_{n}\right)$ shown in Fig.5.

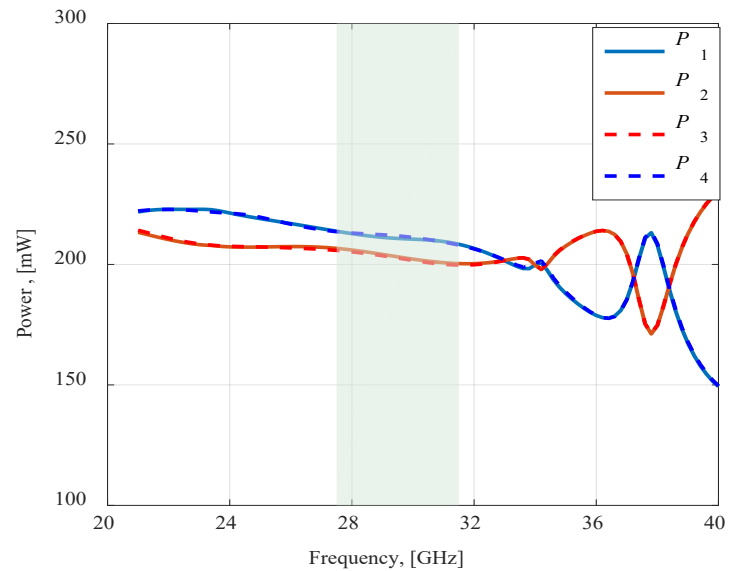

Fig. 7. Simulated active (solid) and passive (dashed) reflection of the $50-\Omega$ microstrip ports, as shown in Fig.5.

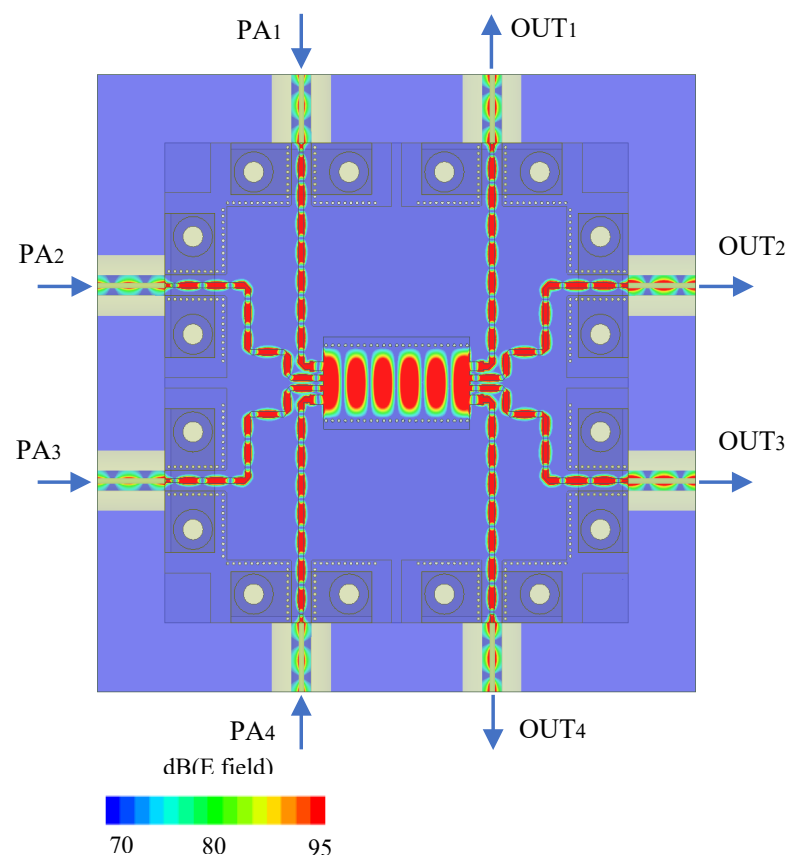

Fig. 8. Simulated $E$-field amplitude distribution for the proof-of-concept prototype, when the input ports are uniformly excited at $31.5 \mathrm{GHz}$ (real part).
The E-field distribution inside the combined back-toback structure, intended for experimental verification (to be presented in future), is shown in Fig. 8., This simulation revealed an undesired field leakage between the dielectricfilled gap formed by the connector body. To remove this effect, both additional via holes and a slight tapering of the TL near the central pin of the connector (not visible in Fig. 8.) were introduced. After optimization, the reflection coefficient in the desired frequency range was shown to satisfy the requirements.

The active reflection coefficients of the $50-\Omega$ input ports that were obtained for the optimized connector interface are shown in Fig. 9. Ripples up to $-20 \mathrm{~dB}$ are visible, which are produced by the connectors and bent microstrip TLs. These ripples can be removed by the designed 2-port TRL calibration kit, which consists of three standards: (i) Thru (T), where two error boxes are connected; (ii) Reflect (R), where the error box is grounded by a via, and; (iii) line (L), where the error boxes are connected through the quarterwavelength segment, corresponding to the central frequency (29.5 GHz).

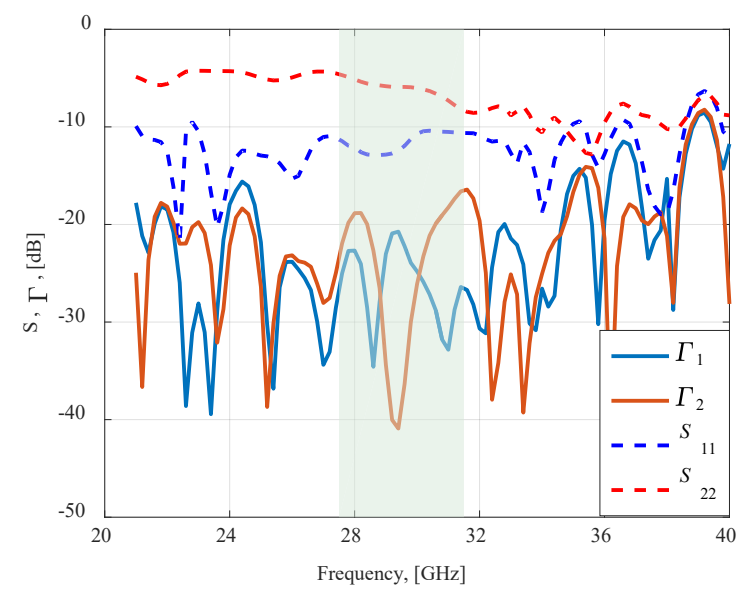

Fig. 9. Simulated active (solid) and passive (dashed) reflection coefficient of the $50-\Omega$ microstrip ports of the prototype, as shown in Fig.8.

\section{DESIGN OF THE PROTOTYPE}

The designed prototype is a passive back-to-back structure, which has 4 input and 4 output $50-\Omega$ coaxial ports for testing with a standard VNA (see Fig. 10). The structure is built on a hybrid multilayer PCB with edge metallization, which is formed by stacking two dielectric material layers. The top RT4350 laminate has a substrate thickness of 0.254 $\mathrm{mm}$ and relative dielectric constant of $\varepsilon_{r}=3.66$. The bottom hardback substrate is FR4, which makes the structure more rigid.

The dissipation factor of RT4350 is low ( $\tan \delta @ 10 \mathrm{GHz}$ $=0.0037)$, which extends the applicability of this laminate to Ka-band and above. Inner metal layers of the hybrid structure can be also used in the future for routing, bias, or control lines of an active device. The PCB has on overall size of approximately $46 \times 46 \mathrm{~mm}^{2}$ and is bolted by $4 \times \mathrm{M} 1.6$ $\mathrm{mm}$ screws to an aluminum support block. 
Figure 11 shows three parts of the model:

- the $1^{\text {st }}$ part is the proposed transition between the SIW and the multiple transmission lines (TL) (a),

- the $2^{\text {nd }}$ part is the set of routing microstrip lines that are needed for testing (b),

- the $3^{\text {rd }}$ part is the corresponding connector interface (c).

Due to strong electromagnetic coupling effects between the transmission lines in the SIW region, the device under test (DUT) includes divergent lines to make the routing lines to the connectors (light gray color) virtually independent. In this case, we can use a 2-port only calibration kit to remove the effect of the routing lines and connectors from the measurement results.

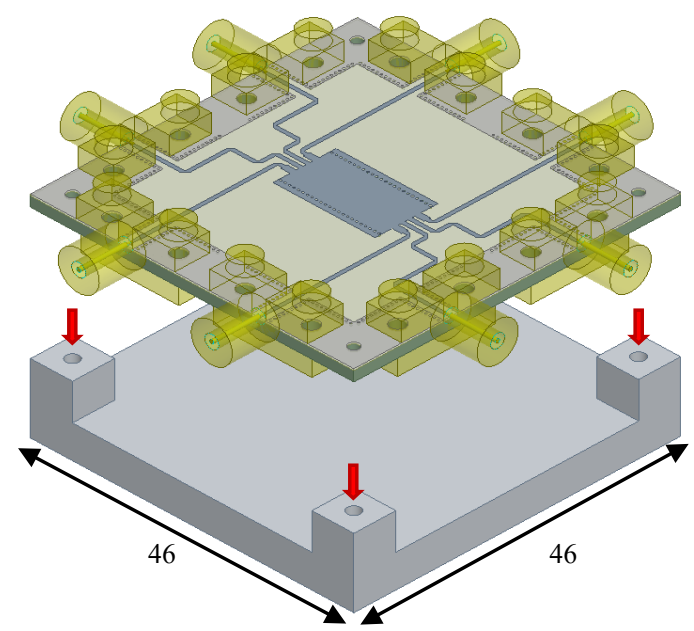

Fig. 10. A mechanical model of the 8-port back-to-back prototype.

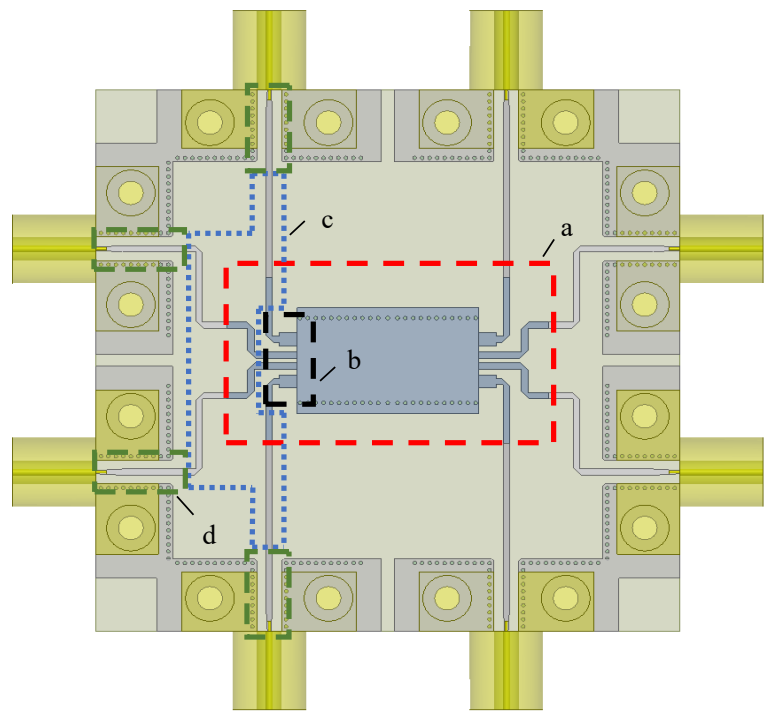

Fig. 11. The detailed model of the proof-of-concept demonstrator: (a) the entire back-to-back structure including two connected transitions, (b) the proposed transition between SIW and four short and strongly-coupled transmission lines, (c) $50-\Omega$ routing microstrip lines that decouple the transmission lines at the ports of the back-to-back for the purpose of testing, (d) connector interface regions.

\section{CONCLUSIONS}

A new transition for interfacing an array of four parallel amplifiers to a single substrate integrated waveguide has been optimized and examined. The predicted active reflection coefficients of all ports are better than $-30 \mathrm{~dB}$ over the desired frequency range $(27.5-31.5 \mathrm{GHz})$, corresponding to a $50 \%$ relative bandwidth. Furthermore, a nearly uniform power distribution across the parallel ports confirms that the power amplifiers in the array can be utilized effectively. A proof-of-concept prototype with calibration kit is under construction; experimental results are to be presented later.

The concept is expected to play an important role in future mm-wave communication systems and MMIC designs, where both high-power generation and cost efficiency are important requirements.

\section{ACKNOWLEDGMENT}

The work is a part of the «Silicon-based Ka-band massive MIMO antenna systems for new telecommunication services (SILIKA)» project, funded by the European Union's Horizon 2020 research and innovation program under the Marie Skłodowska Curie grant agreement \#721732. The authors wish to thank Ir. Marcel Geurts from NXP Semiconductors (The Netherlands) for providing information on the 4-channel NXP beamformer/amplifier chip and its pinout configuration.

\section{REFERENCES}

[1] Ericsson, "On mm-wave technologies for NR (New Radio)," 3GPP TSG-RAN WG4 \#79, R4-164226. Available on-line: http://www.3gpp.org/ftp/tsg_ran/WG4_Radio/TSGR4_79/Docs/R4164226.zip.

[2] Ericsson technology review "The new microwave backhaul frontier", February 2017. Available on-line: https://www.ericsson.com/assets /local/publications/ericsson-technology-review/docs/2017/etr-beyond100ghz.pdf

[3] K. H. An, O. Lee, H. Kim, D. H. Lee, J. Han, K. S. Yang, Y. Kim, J. J. Chang, W.Woo, C.-H. Lee, H. Kim, and J. Laskar, "Powercombining transformer techniques for fully-integrated CMOS power amplifiers," IEEE J. Solid-State Circuits, vol. 43, no. 5, pp. 1064 1075, May 2008.

[4] A. Roev, R. Maaskant, M. Ivashina, A. Höök "Wide-Band Spatially Distributed TE10 Substrate Integrated Waveguide Transition for High-Power Generation at mm-Wave Frequencies", IEEE International Symposium on Antennas and Propagation (ISAP2017), Phuket, Thailand, 30 Oct. - 2 Nov., 2017.

[5] D. Deslandes, "Design equations for tapered microstrip-to-substrate integrated waveguide transitions". IEEE MTT-S Int. Microwave Symp. Digest, Anaheim, CA, USA, 23-28 May 2010, pp. 704-707.

[6] A. Aljarosha, A. U. Zaman and R. Maaskant, "A Wideband Contactless and Bondwire-Free MMIC to Waveguide Transition," IEEE Microwave and Wireless Components Letters, vol. 27, no. 5, pp. 437-439, May 2017. 